\title{
Genetic analysis of the interaction between Allium species and arbuscular mycorrhizal fungi
}

\author{
Guillermo A. Galván • Thomas W. Kuyper • \\ Karin Burger · L. C. Paul Keizer · Rolf F. Hoekstra • \\ Chris Kik · Olga E. Scholten
}

Received: 25 July 2010/Accepted: 22 November 2010/Published online: 11 January 2011

(C) The Author(s) 2011. This article is published with open access at Springerlink.com

\begin{abstract}
The response of Allium cepa, A. roylei, A. fistulosum, and the hybrid A. fistulosum $\times$ A. roylei to the arbuscular mycorrhizal fungus (AMF) Glomus intraradices was studied. The genetic basis for response to AMF was analyzed in a tri-hybrid A. cepa $\times($ A. roylei $\times$ A. fistulosum) population. Plant response to mycorrhizal symbiosis was expressed as relative mycorrhizal responsiveness $\left(\mathrm{R}^{\prime}\right)$
\end{abstract}

Communicated by I. Paran.

Electronic supplementary material The online version of this article (doi:10.1007/s00122-010-1501-8) contains supplementary material, which is available to authorized users.

G. A. Galván · K. Burger · C. Kik · O. E. Scholten $(\bowtie)$

Department of Plant Breeding, Plant Research International,

Wageningen University and Research Centre,

P.O. Box 16, 6700 AA Wageningen, The Netherlands

e-mail: Olga.Scholten@wur.nl

\section{G. A. Galván}

Department of Producción Vegetal, Centro Regional Sur (CRS), Facultad de Agronomía, Universidad de la República,

Progreso, Uruguay

T. W. Kuyper

Department of Soil Quality, Wageningen University,

P.O. Box 47, 6700 AA Wageningen, The Netherlands

\section{C. P. Keizer}

Department of Biometris, Wageningen University and Research Centre, P.O. Box 100, 6700 AC Wageningen, The Netherlands

R. F. Hoekstra

Department of Genetics, Wageningen University,

P.O. Box 16, 6700 AA Wageningen, The Netherlands

C. Kik

Centre for Genetic Resources (CGN), The Netherlands.

Wageningen University and Research Centre,

P.O. Box 16, 6700 AA Wageningen, The Netherlands and absolute responsiveness (R). In addition, the average performance (AP) of genotypes under mycorrhizal and non-mycorrhizal conditions was determined. Experiments were executed in 2 years, and comprised clonally propagated plants of each genotype grown in sterile soil, inoculated with $G$. intraradices or non-inoculated. Results were significantly correlated between both years. Biomass of non-mycorrhizal and mycorrhizal plants was significantly positively correlated. $\mathrm{R}^{\prime}$ was negatively correlated with biomass of non-mycorrhizal plants and hence unsuitable as a breeding criterion. $\mathrm{R}$ and AP were positively correlated with biomass of mycorrhizal and non-mycorrhizal plants. QTLs contributing to mycorrhizal response were located on a linkage map of the A. roylei $\times$ A. fistulosum parental genotype. Two QTLs from A. roylei were detected on chromosomes 2 and 3 for R, AP, and biomass of mycorrhizal plants. A QTL from A. fistulosum was detected on linkage group 9 for AP (but not R), biomass of mycorrhizal and non-mycorrhizal plants, and the number of stem-borne roots. Co-segregating QTLs for plant biomass, R and AP indicate that selection for plant biomass also selects for enhanced R and AP. Moreover, our findings suggest that modern onion breeding did not select against the response to AMF, as was suggested before for other cultivated species. Positive correlation between high number of roots, biomass and large response to AMF in close relatives of onion opens prospects to combine these traits for the development of more robust onion cultivars.

$\begin{array}{ll}\text { Abbreviations } \\ \text { AMF } & \text { Arbuscular mycorrhizal fungi } \\ \text { AM } & \text { Arbuscular mycorrhizal } \\ \text { AP } & \text { Average performance } \\ \text { NM } & \text { Non-mycorrhizal } \\ \text { R } & \text { Absolute mycorrhizal responsiveness }\end{array}$


$\mathrm{R} \quad$ Relative mycorrhizal responsiveness

REML Residual maximum likelihood analysis

RF-hybrid A. roylei $\times$ A. fistulosum parental genotype

\section{Introduction}

In order to obtain high yields of onion (Allium cepa L.), large amounts of fertilizers are used in high-input cropping systems (Bosch-Serra and Currah 2002). These fertilizers are costly, and as the crop takes up only a minor part of these inputs (Greenwood et al. 1982), negative impacts on the environment can be expected. In organic and low-input cropping systems, a balance is sought between yield and goals that minimize impacts on the environment (Rossing et al. 2007). Therefore, synthetic fertilizers are applied at lower rates in low-input farming systems than in conventional ones, or are even completely excluded as in organic systems. Thus, crop yield and economic results may be lower. A Dutch survey showed that onion yields in organic cultivation were 54\% lower than those in conventional cultivation systems (Galván et al. 2009). Both different practices (e.g. planting distance) and differences in soil nutrient supply cause this yield gap. In the study by Galván et al. (2009), the average phosphorus concentration $\left(\mathrm{P}_{\mathrm{w}}\right)$ in organic soils was $27 \%$ lower than in conventional soils. Onion has a sparse and shallow rooting system, consisting mainly of stem-borne roots that rarely branch and lack root hairs (Portas 1973, Greenwood et al. 1982). Because P diffuses very slowly through the soil, plants with poor rooting systems cannot maintain an adequate $\mathrm{P}$ uptake and therefore yields are hampered (Mengel and Kirkby 2001).

Various plant-breeding strategies can contribute to maintain high yields in organic and low-input agricultural systems by improving P uptake and P use. One strategy is the development of cultivars with improved rooting systems (Lynch 2007). De Melo (2003) proposed to use Allium fistulosum L. as a donor species because it has a larger and denser rooting system than onion. Although progeny plants of A. cepa $\times$ A. fistulosum are partially sterile, gene transfer from A. fistulosum to A. cepa is possible by the use of $A$. roylei Stearn as a bridge species (Khrustaleva and Kik 1998, 2000). De Melo (2003) investigated the inheritance of root traits in an A. cepa $\times($ A. roylei $\times$ A. fistulosum) population. QTLs for traits of the rooting system were found, indicating that breeding for an improved rooting system in onion is possible (De Melo 2003).

A second breeding strategy may be the selection for enhanced response to the symbiosis with arbuscular mycorrhizal fungi (AMF). These fungi naturally occur in soils. In mycorrhizal symbioses, the fungus obtains carbohydrates from the plant, whereas the plant improves its nutrient acquisition, particularly $\mathrm{P}$, among other benefits (Stribley 1990). Improved nutrient uptake depends on the build up of a mycelial network beyond the depletion zone (George et al. 1995, Mengel and Kirkby 2001). As a result, plant biomass of mycorrhizal plants is larger than that of non-mycorrhizal plants (reviewed by Lekberg and Koide 2005, Hoeksema et al. 2010).

The response to mycorrhiza is dependent on $\mathrm{P}$ availability in the soil. Under high P-levels, smaller growth benefits from mycorrhiza in onions were observed than in P-deficient soils (Hayman and Mosse 1971). Therefore, contributions from the symbiosis with AMF are particularly expected in organic and low-input agricultural systems (Ryan and Graham 2002; Gosling et al. 2006).

Intraspecific differences in the response to mycorrhiza have been observed in various crops, for example, wheat cultivars (Hetrick et al. 1993), maize inbred lines (Kaeppler et al. 2000), cultivars of A. fistulosum (Tawaraya et al. 2001) and onion cultivars (Powell et al. 1982). Such differences in response indicate a genetic basis for the plantAMF interaction. Therefore, the possibility and desirability of breeding for an enhanced response to mycorrhiza was suggested by several authors (Parke and Kaeppler 2000; Plenchette et al. 2005; Gosling et al. 2006; Sawers et al. 2008). These authors hypothesized that cultivars that benefit more from this symbiosis would contribute to a more sustainable agriculture as amounts of fertilizers could be reduced (Ryan and Graham 2002). Genomic regions quantitatively linked to the response to AMF were identified for wheat (Hetrick et al. 1995) and maize (Kaeppler et al. 2000). Up to now, no practical application of that knowledge has been reported.

The existence of various plant strategies to enhance P-uptake raises the question to what extent the different strategies are additive or have to be traded off. For rice, Gao et al. (2007) reported that the ability of non-mycorrhizal rice to acquire nutrients was negatively correlated with mycorrhizal responsiveness. For bean, Lynch (2007) showed that the effects of root hairs (as part of an improved rooting system) and of AMF on plant growth were additive. Since a high response to AMF was described for A. fistulosum (Tawaraya et al. 2001), the question arises whether this species could also be used to improve the response to mycorrhiza in onion.

The aim of the present study was to investigate the genetic basis that underlies the interaction between relatives of onion and AMF, more specifically the response of these plants to AMF. Quantitative trait loci (QTLs) involved in that interaction were mapped on an AFLP linkage map. Other traits such as plant biomass, number of roots, and bulbing ability were also linked to this AFLP linkage map. 


\section{Materials and methods}

Plant material

Allium cepa cultivar 'Jumbo' (Rijnsburger group), A. roylei (PRI-1270), and A. fistulosum (PRI-2002-232) were tested for the response to mycorrhiza. The hybrid A. fistulosum $\times$ A. roylei (RF-hybrid) and the tri-hybrid population A. cepa $\times($ A. roylei $\times$ A. fistulosum $)$ were developed as described by Khrustaleva and Kik (1998). Each tri-hybrid genotype has a set of chromosomes from A. cepa, and a set of chromosomes from A. roylei, or A. fistulosum, or recombinants between them.

An offspring of 96 tri-hybrid genotypes was used to develop a linkage map of the RF-hybrid. The parental species, the RF-hybrid, and each genotype of the tri-hybrid were clonally multiplied in vitro in order to have replicates for the experiments. Sections of the basal plates were used as initial explants, as described by De Melo (2003), and clonally multiplied by successive divisions of the basal plates.

\section{Evaluation of the response to AMF}

The evaluation of the parental species, the RF-hybrid, and the tri-hybrid population was executed in 2006 and 2007. The experiment comprised 77 tri-hybrid genotypes in 2006 and 83 in 2007, of which 68 genotypes were evaluated in both years. Plantlets grown in vitro for 3-4 weeks with 2-3 leaves and well-developed roots were transferred to trays and covered with a transparent lid that was further opened daily. The trays contained a potting mixture (steamed peatsoil and sand, 2:1 ratio). After 4 weeks, plants were transferred to individual pots 2.11 in size in 2006 and 3.31 in 2007. The pots contained a mixture of gamma-irradiated clay soil, sand and perlite (6:1:1 ratio). The clay soil was collected from an organic farmland. Chemical composition of the soils was collected in both years and showed the $\mathrm{P}$ levels were very low in 2006 (below the detection limit) and low in 2007 (Table 1).

Glomus intraradices Schenck and Smith inoculum was kindly provided by Dr. Y. Kapulnik (Volcani Center, Israel), as spores in dry vermiculite (Alkan et al. 2003). A full spoon of inoculum (ca. $1.7 \mathrm{~g}$ ) was added to each pot in a hole made for transplanting. The same inoculum previously

Table 1 Average chemical parameters of the clay soils collected in 2006 and 2007 (pH measured in $1 \mathrm{M} \mathrm{KCl}$, nutrients measured in water)

\begin{tabular}{lllll}
\hline Year & $\mathrm{pH}$ & $\mathrm{P}(\mathrm{mg} / \mathrm{kg})$ & $\mathrm{Ca}(\mathrm{mg} / \mathrm{kg})$ & $\mathrm{K}(\mathrm{mg} / \mathrm{kg})$ \\
\hline 2006 & 7.0 & $<0.2$ & 9.6 & 2.3 \\
2007 & 6.8 & 0.2 & 12.8 & 3.1 \\
\hline
\end{tabular}

autoclaved (60 min, two times) was added in a similar way to the pots belonging to the non-mycorrhizal control. A soil wash was added to both the AM and NM treatment.

Six replicates (individual plants) of each Allium species, the RF-hybrid and the tri-hybrid genotypes were inoculated with $G$. intraradices and six replicates were kept as nonmycorrhizal control. Genotypes were randomized within six blocks of AM and NM treatment each, and placed on separate tables. Experiments took place in a compartment with controlled relative humidity and temperature set at $22-18^{\circ} \mathrm{C}$ (day-night). Nitrogen as diluted $\mathrm{Ca}\left(\mathrm{NO}_{3}\right)_{2}$ was applied 7 weeks after transplanting, at a rate of $160 \mathrm{mg} \mathrm{N} \mathrm{kg}^{-1}$ soil. Plants were harvested 14 weeks after transplanting. Total aboveground fresh and dry weights were determined. Aboveground parts were partitioned in leaves and bulb/false stem (lower $5 \mathrm{~cm}$ ) weight, and their individual weights assessed. The number of leaves, false stems and plant height (length from basal plate to the longest green leaf tip) were recorded. The number of stem-borne roots was also recorded. Assessing belowground biomass was not possible, because detachments at harvest prevented accurate measurements.

Indices for the response to mycorrhiza

Response to AMF was assessed by calculating relative mycorrhizal responsiveness as proposed by Baon et al. (1993): $R^{\prime}=(\mathrm{AM}-\mathrm{NM}) / \mathrm{NM}$, the weight difference between mycorrhizal and non-mycorrhizal plants divided by the weight of non-mycorrhizal plants. Because of the problematic nature of that dimensionless index (see "Results" and "Discussion"), two further indices that could be useful for plant breeding while taking plant response from mycorrhiza into account, were used: (1) absolute mycorrhizal responsiveness $(\mathrm{R})$, the difference in total weight between $\mathrm{AM}$ and NM treatments: $R=\mathrm{AM}-\mathrm{NM}$ (Janos 2007; Sawers et al. 2010). This variable indicates the biomass increment due to the presence of AMF at a given $\mathrm{P}$ level, (2) average performance (AP), the average plant weight of $\mathrm{AM}$ and $\mathrm{NM}$ treatments: $\mathrm{AP}=(\mathrm{AM}+\mathrm{NM}) / 2$. This index takes into account plant performance averaged over conditions of variable availability of mycorrhizal inoculum (see Fig. 1 as an illustrative example). R and AP were calculated for plant total, leaves and bulb/false stem dry weight, and number of stem-borne roots.

Residual Maximum Likelihood (REML) analysis was performed in Genstat 9.2 (Lawes Agricultural Trust, Rothamsted Exp. St., UK, 2006). Significant differences for mycorrhiza and genotype effects were established with Fisher's-protected LSD. All variables except plant height were square root transformed. The relationships between indices for the response to mycorrhiza and plant traits were studied by Pearson correlation analysis. As tri-hybrid genotypes segregated for bulbing ability, the relationship 

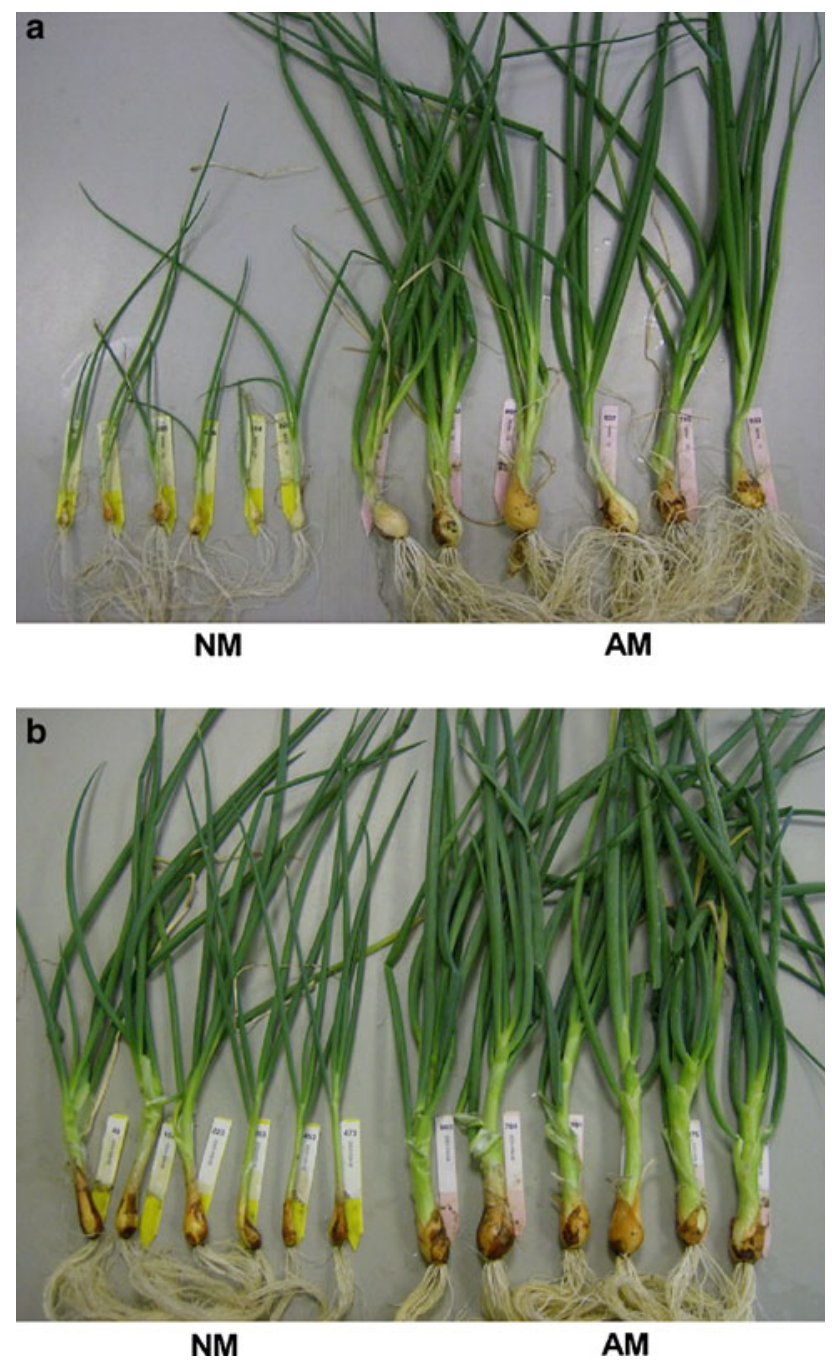

Fig. 1 Two examples of tri-hybrid genotypes with contrasting response to the inoculation with $G$. intraradices, in the nonmycorrhizal (NM) and mycorrhizal (AM) treatments after harvesting experiment 2007. a Genotype unable to grow in a P-deficient soil without mycorrhiza, having very large $\mathrm{R}^{\prime}$ (1909\%), large R (6.68 g) and relatively low AP (3.69 g). b Genotype less dependent on AMF, having smaller $\mathrm{R}^{\prime}(132 \%)$, similarly large $\mathrm{R}(6.22 \mathrm{~g})$ and much higher AP $(7.82 \mathrm{~g})$

with this trait was also studied. In order to do that, genotypes were classified in four categories regarding the average bulbing index $(\mathrm{BI}=$ BulbDiameter/NeckDiameter), as follows: null $(\mathrm{BI}=1.0-1.6)$, low (1.6-2.4), medium (2.4-2.7), and high (>2.7) degree of bulbing. The Bulb Diameter is the widest diameter of the bulb, and the Neck Diameter is the diameter of the false stem on top of the bulb. R, AP, and plant biomass for genotypes belonging to these four bulbing classes were compared by REML analysis. Significant differences between parental species (including the RF-hybrid) and differences between bulbing categories of the tri-hybrid were established with Fischer'sprotected LSD.
AFLP linkage analysis and QTL mapping

DNA of each tri-hybrid genotype, the parental lines and the RF-hybrid was isolated from young leaves, following the miniprep protocol described by Van Heusden et al. (2000). AFLP $^{\circledR}$ (Keygene B.V., The Netherlands) reactions were carried out according to Vos et al. (1995). Two pairs of restriction enzymes were used, namely EcoRI/MseI and PstI/MseI. Because of the large genome size in Allium species, pre-amplifications were done with three selective nucleotides $(+1,+2)$ and the selective amplifications with seven nucleotides $(+3,+4)$ for the $E c o \mathrm{RI} / M s e \mathrm{I}$ enzyme pairs, and six $(+3,+3)$ for the PstI/MseI pairs (Van Heusden et al. 2000). A total of 22 primer pairs were used in the selective amplifications (Table 1). AFLP fragments originating exclusively from A. roylei or A. fistulosum were scored using Quantar (Keygene B.V., The Netherlands). Markers were named as described by van Heusden et al. (2000). For instance, E38M52G-202F refers to restriction enzymes EcoI and MseI, primers E38 and M52, 'G' identifies the additional seventh base, '202' is the estimated length of the fragment, and ' $\mathrm{F}$ ' or ' $\mathrm{R}$ ' means that the marker is specific for A. fistulosum or A. roylei respectively.

A linkage map for the RF-hybrid was calculated using JoinMap 3.0 (Van Ooijen and Voorrips 2001). Populationtype was set to haploid, and linkage groups were separated with a threshold $\mathrm{LOD} \geq 4$. Kosambi's mapping function was used to calculate map positions of the markers. Linkage groups were assigned to chromosomes based on AFLP markers in common with previous maps (Van Heusden et al. 2000; de Melo 2003). Marker order was fixed for Chromosomes 5 and 8 according to Khrustaleva et al. (2005).

Quantitative trait loci (QTLs) analysis was performed using MapQTL ${ }^{\circledR} 4.0$ (Van Ooijen et al. 2002). KruskalWallis test was applied to determine the association between each individual marker in the map and the target traits. QTLs were identified by the multiple QTL mapping (MQM) procedure (Jansen 1993; Jansen and Stam 1994), and were regarded significant at LOD threshold value with $p<0.05$. This threshold value was estimated for each trait based on population type and 1,000 times genome-wide permutations. Linkage maps and QTL figures were drawn in MapChart (Voorrips 2002).

\section{Results}

Response to mycorrhiza in Allium

Non-mycorrhizal plants (NM) remained free of mycorrhiza. In 2006 and 2007, total dry weight of AM plants was larger than that of NM plants for the parental species and 
the RF-hybrid (REML analysis, $p<0.05$ ). Allium roylei had the lowest biomass, whereas differences in plant biomass between A. cepa, A. fistulosum and the RF-hybrid were not significant (Table 2). For most tri-hybrid genotypes, the weight of AM plants was also significantly larger than that of NM plants. 72 genotypes (94\%) in 2006 and 80 genotypes (96\%) in 2007 did have significantly more biomass in the mycorrhizal condition. Maximum biomass in the tri-hybrid population (both when AM and NM) was larger than that of the best performing parent, while minimum biomass was lower than that of $A$. roylei, the parent with lowest biomass (transgressive segregation) (Table 3 ).

Differences between AM and NM treatments were larger in 2007 than in 2006 (Fig. S1). Mean total dry weight of AM plants was 2.5 times higher than that of NM plants in 2006, and 4 times in 2007 (Table 3). Performance of mycorrhizal plants in 2006 and 2007 was significantly correlated ( $r=0.76, n=68, p<0.001)$. Performance of non-mycorrhizal plants in both years was also significantly correlated ( $r=0.38, n=68, p<0.01)$. Weight of NM and AM plants was positively correlated in both years (Fig. 2).

Relative mycorrhizal responsiveness $\left(\mathrm{R}^{\prime}\right)$ of tri-hybrid genotypes was negatively correlated with biomass of NM plants (Fig. 3). Because this negative relationship implies that selection for higher responsiveness results in selection for smaller plants in the non-mycorrhizal condition, we used two further variables to express the benefit that plants obtain from the symbiosis: absolute mycorrhizal responsiveness (R) and average performance (AP).

Correlations between biomass for AM and NM conditions, and with R and AP for 2006 and 2007 are shown in Fig. 3. R and AP were very significantly correlated with biomass of AM plants, while these correlations with biomass of NM plants were lower and not always significant. $\mathrm{R}$ and AP were also significantly correlated in 2006 and 2007 (data not shown).

Allium cepa had the lowest number of stem-borne roots, and A. fistulosum the highest (Table 2). The RF-hybrid had more roots than A. fistulosum in 2006, but less in 2007. Among tri-hybrid genotypes, the average number of stemborne roots showed transgressive segregation (Table 2). The number of roots in the AM treatment was positively correlated with total dry weight $(r=0.59$ and 0.69$), \mathrm{R}$ $(r=0.45$ and 0.65$)$, and AP $(r=0.62$ and 0.64$)$ (values respectively for experiments 2006 and 2007, $p<0.001$ in all cases).

Plant height, number of leaves and leaf dry weight were lowest in A. cepa, but bulb dry weight was highest for $A$. cepa. $\mathrm{R}$ and AP calculated based on these traits showed the same contrasting pattern between A. cepa and the other parental material (Fig. S2). Tri-hybrid genotypes were classified in four bulbing classes (Fig. 4). There were no significant differences in bulb (or false-stem) weight
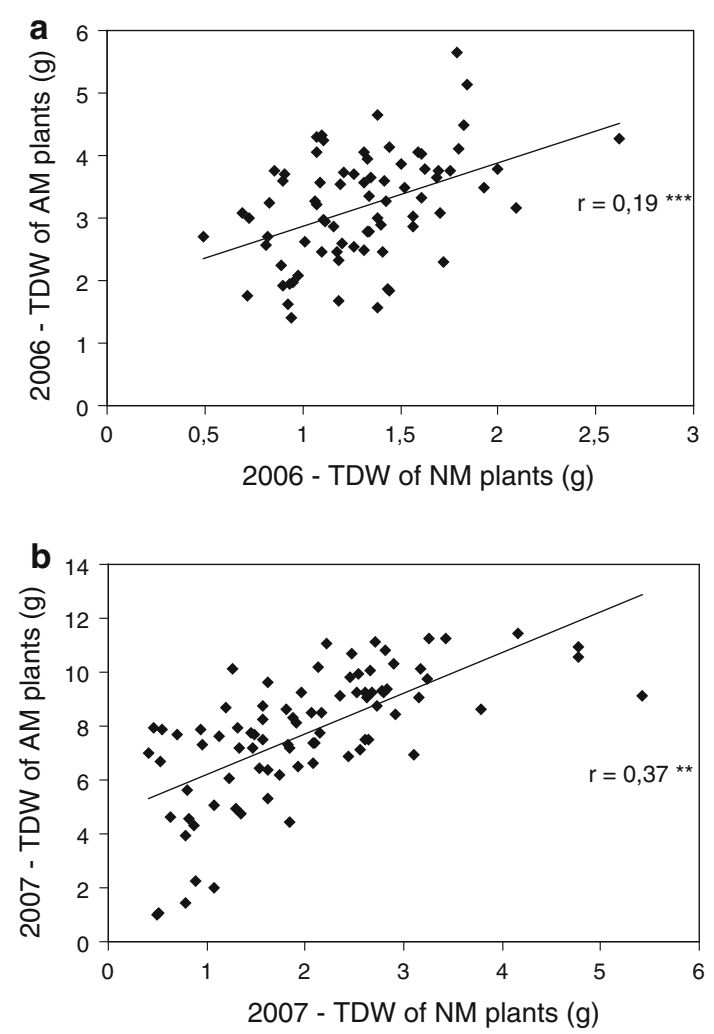

Fig. 2 Genetic variation in the tri-hybrid Allium population. Relationship between total dry weight (TDW) of non-mycorrhizal (NM) and mycorrhizal (AM) plants in experiments a 2006 and b 2007. Pearson correlations $(* * p<0.01 ; * * * p<0.001)$

between the four classes, but genotypes with high degree of bulbing had significantly lower AM total weight, leaf weight and $\mathrm{R}$ than the other bulbing classes (Table 4). In 2006, no differences between bulbing levels were found for $\mathrm{AP}$, whereas in 2007, AP was also lower for genotypes with high degree of bulbing. Among genotypes with high degree of bulbing, two genotypes in 2006 (17\%) and five genotypes in 2007 (33\%) presented early bulbing and leaf senescence before harvesting.

AFLP mapping and QTL analysis

A total of 359 polymorphic AFLP markers originating from either A. roylei or A. fistulosum were analyzed. Among these, 143 markers were mapped on 15 linkage groups (LOD $\geq 4$ ). Eight main groups (LOD 4-5.4) were assigned to chromosomes based on markers mapped earlier (Van Heusden et al. 2000, De Melo 2003). The resulting linkage map for the RF-hybrid contained 111 markers in eight linkage groups covering $886 \mathrm{cM}$. Marker positions on the chromosomes were calculated without forcing, and an overall mean marker Chi-Square contribution of 2.24 was obtained. Mean linkage group size was $110.7 \mathrm{cM}$, and mean marker interval was $8.1 \mathrm{cM}$. The map had four gaps 
Table 2 Amplified fragment length polymorphism (AFLP) adapters and primers used in the ligation and amplification steps, and their sequences

\begin{tabular}{ll}
\hline Adapters & EcoRI adapters \\
& MseI adapters \\
& PstI adapters \\
& E00 \\
M00 & P00 \\
Universal primers & E01 (E00+A) - $02(\mathrm{M} 00+\mathrm{C})$ \\
P01 (P00+A) - M01 (M00+A) & P01 (P00+A) - M02 (M00+C)
\end{tabular}

Primer pairs in the selective amplification

\begin{tabular}{|c|c|}
\hline \multirow{3}{*}{ E35 (E00+ACA) } & $\mathrm{M} 52 \mathrm{~A}(\mathrm{M} 00+\mathrm{CCCA})$ \\
\hline & M52C (M00+CCCC) \\
\hline & M52T (M00+CCCT) \\
\hline $\mathrm{E} 36(\mathrm{E} 00+\mathrm{ACC})$ & M52C (M00+CCCC) \\
\hline \multirow[t]{3}{*}{ E37 (E00+ACG) } & M52A (M00+CCCA) \\
\hline & M52C (M00+CCCC) \\
\hline & M52G (M00+CCCG) \\
\hline \multirow[t]{2}{*}{ E38 $(\mathrm{E} 00+\mathrm{ACT})$} & M52G (M00+CCCG) \\
\hline & M52T (M00+CCCT) \\
\hline \multirow[t]{2}{*}{ P31 (P00+AAA) } & M33 (M00+AAG) \\
\hline & M35 (M00+ACA) \\
\hline \multirow[t]{7}{*}{ P35 (P00+ACA) } & M32 (M00+AAC) \\
\hline & M33 (M00+AAG) \\
\hline & M34 (M00+AAT) \\
\hline & M35 (M00+ACA) \\
\hline & M36 (M00+ACC) \\
\hline & M47 (M00+CAA) \\
\hline & M50 (M00+CAT) \\
\hline \multirow[t]{2}{*}{ P38 (P00+ACT) } & M47 (M00+CAA) \\
\hline & M48 (M00+CAC) \\
\hline \multirow[t]{2}{*}{ P43 (P00+ATA) } & M36 (M00+ACC) \\
\hline & M51 (M00+CCA) \\
\hline
\end{tabular}

5'-CTCGTAGACTGCGTACC-3'

$3^{\prime}$-CTGACGCATGGTTAA- ${ }^{\prime}$

5'-GACGATGAGTCCTGAG-3'

3'-TACTCAGGACTCAT-5'

5'-CTCGTAGACTGCGTACATGCA-3'

3'-TGTACGCAGTCTAC-5'

5'-GACTGCGTACCAATTC-3'

5'-GATGAGTCCTGAGTAA-3'

5'-GACTGCGTACATGCAG-3' larger than $18 \mathrm{cM}$ in chromosomes 3 and 5 , and in distal regions of chromosomes 1 and 7 .

The remaining additional linkage groups (linkage groups 9-15) could not be associated to any chromosome because they only consisted of AFLP markers not reported before. These linkage groups were included in the QTL analysis. QTLs for 'traits' that indicate response to mycorrhiza were detected on chromosomes 2, 3, and linkage group 9 (Table 5; Fig. 5). A first QTL was located on the central part of chromosome 2 and associated with A. roylei alleles. This QTL was significant for $\mathrm{R}$ in 2006 and 2007, and AP in 2006. The estimated position for $\mathrm{R}$ differed between both years. This chromosomal region co-segregated with QTLs for total dry weight, leaf dry weight and plant height of AM plants in 2006. A second QTL was located on a distal part of chromosome 2, also associated with A. roylei alleles. This QTL was significant for R, AP and AM total dry weight but only in 2007.

A third QTL was detected on a distal part of chromosome 3, associated with one A. roylei marker (Table 5; Fig. 5). This QTL was significant for R in 2007 and AP in 2006 and co-segregated with QTLs for total dry weight of AM and NM plants in 2006, and AM plants in 2007. In addition, this region co-segregated with QTLs for plant height and leaf dry weight in both years. QTLs detected for $\mathrm{R}$ explained 29.3 and $50.1 \%$ of the total variation in 2006 and 2007 respectively (Table 5). 
Table 3 Total dry weight, number of stem-borne roots per plant of non-mycorrhizal (NM) and mycorrhizal plants (AM), and indices for the response to AMF of the parental material and the tri-hybrid genotypes in experiments 2006 and 2007

\begin{tabular}{|c|c|c|c|c|c|c|c|c|}
\hline \multirow[t]{2}{*}{ Plant material } & \multicolumn{4}{|c|}{ Total dry weight $(\mathrm{g})$} & \multicolumn{4}{|c|}{$\mathrm{Nr}$ of stem-borne roots per plant } \\
\hline & $\mathrm{NM}^{\mathrm{a}}$ & $\mathrm{AM}^{\mathrm{a}}$ & $\mathrm{R}^{\mathrm{b}}$ & $\mathrm{AP}^{\mathrm{c}}$ & $\mathrm{NM}^{\mathrm{a}}$ & $\mathrm{AM}^{\mathrm{a}}$ & $\mathrm{R}^{\mathrm{b}}$ & $\mathrm{AP}^{\mathrm{c}}$ \\
\hline \multicolumn{9}{|l|}{ Experiment 2006} \\
\hline Allium сера & $1.24 \mathrm{bc}$ & $2.79 \mathrm{a}$ & 1.55 & 2.01 & $8.6 \mathrm{f}$ & $11.1 \mathrm{ef}$ & 2.5 & 9.9 \\
\hline Allium fistulosum & $0.70 \mathrm{c}$ & $1.95 \mathrm{ab}$ & 1.25 & 1.33 & $19.9 \mathrm{~cd}$ & $31.4 \mathrm{~b}$ & 11.5 & 25.7 \\
\hline Allium roylei & $0.54 \mathrm{~d}$ & $1.58 \mathrm{~b}$ & 1.04 & 1.06 & 11.3 ef & $16.3 \mathrm{de}$ & 5.0 & 13.8 \\
\hline RF-hybrid & $1.20 \mathrm{bc}$ & $2.88 \mathrm{a}$ & 1.68 & 2.04 & $27.2 \mathrm{bc}$ & $43.7 \mathrm{a}$ & 16.5 & 35.5 \\
\hline \multicolumn{9}{|c|}{ Tri-hybrid genotypes $(n=77)$} \\
\hline Mean & 1.29 & 3.17 & 1.88 & 2.23 & 15.3 & 25.4 & 10.2 & 20.3 \\
\hline Minimum & 0.45 & 1.30 & 0.23 & 1.19 & 6.3 & 7.5 & 1.2 & 6.9 \\
\hline Maximum & 2.58 & 5.67 & 3.89 & 3.73 & 33.3 & 35.7 & 2.5 & 34.5 \\
\hline \multicolumn{9}{|l|}{ Experiment 2007} \\
\hline Allium сера & $2.00 \mathrm{c}$ & $6.16 \mathrm{a}$ & 4.15 & 4.09 & $3.7 \mathrm{e}$ & $8.2 \mathrm{de}$ & 4.5 & 5.9 \\
\hline Allium fistulosum & $1.49 \mathrm{c}$ & $6.22 \mathrm{a}$ & 4.73 & 3.85 & $30.1 \mathrm{bc}$ & $74.7 \mathrm{a}$ & 44.6 & 52.4 \\
\hline Allium roylei & $0.68 \mathrm{~d}$ & $3.45 \mathrm{~b}$ & 2.77 & 2.06 & $27.0 \mathrm{bc}$ & $19.2 \mathrm{~cd}$ & 7.2 & 15.5 \\
\hline RF-hybrid & $1.53 \mathrm{c}$ & $5.63 \mathrm{a}$ & 4.10 & 3.58 & $11.9 \mathrm{de}$ & $43.5 \mathrm{~b}$ & 16.6 & 35.3 \\
\hline \multicolumn{9}{|c|}{ Tri-hybrid genotypes $(n=83)$} \\
\hline Mean & 1.97 & 7.71 & 5.81 & 4.88 & 21.1 & 38.9 & 17.8 & 30.0 \\
\hline Minimum & 0.37 & 1.18 & 0.68 & 1.01 & 3.0 & 2.4 & -0.6 & 2.7 \\
\hline Maximum & 5.34 & 11.44 & 8.89 & 7.83 & 39.6 & 66.3 & 26.7 & 53.0 \\
\hline
\end{tabular}

${ }^{a}$ Within each experiment, treatment-genotype combinations followed by the same letter do not differ $(p<0.05)$. REML analysis followed by Fischer-potected LSD-test, for square root transformed data

b Absolute responsiveness, as $R=(\mathrm{AM}-\mathrm{NM})$

c Average performance, as $\mathrm{AP}=(\mathrm{AM}+\mathrm{NM}) / 2$

A QTL for AP (but not for R) was located on linkage group 9, and associated with A. fistulosum alleles (Table 5; Fig. 5). This region also harboured QTLs for total dry weight of AM and NM plants in both years, as well as for bulb dry weight of AM plants in both years. A QTL for the number of stem-borne roots was detected also on linkage group 9, which accounted for 19.1 and $17.9 \%$ of the total variation for this trait in 2006 and 2007, respectively.

QTLs for AP on chromosomes 2, 3 and the linkage group 9 accounted for $56 \%$ of the total variation in 2006 and $49 \%$ in 2007 . These three regions accounted also for 40 and $39 \%$ of the variation among genotypes in total dry weight of AM plants in 2006 and 2007, respectively. Other QTLs detected for R and AP were only significant for one of the years, and contributed to a lesser extent in explaining total variation (Table 5).

\section{Discussion}

Response to mycorrhiza in Allium

Allium species and tri-hybrid Allium genotypes benefitted greatly from the inoculation with AMF. Larger plant growth in 2007 compared to 2006 is likely a consequence of larger pot sizes in 2007, as reported before for onion by Bååth and Hayman (1984). Furthermore, differences in P-availability of the soils used could have attributed to the difference. P-availability in 2006 was very low, and in 2007 low, much lower than the reported P-availabilities in organic and conventional onion fields in The Netherlands (Galván et al. 2009). Differences in light availability were unlikely of importance, as 2006 was on average more sunny during the growing season than 2007. The consistent ranking of genotypes in both years, when mycorrhizal, indicates that context-dependency of mycorrhizal performance was minor in this study. The lower correlation of performance of non-mycorrhizal plants in both years is due to the plantlets that at transplanting show a relatively high coefficient of variation, which, in combination with very poor growth under non-mycorrhizal conditions, inevitably resulted in a weaker (but still significant correlations).

Results of this study agree with studies by Hayman and Mosse (1971) who found that the weight of A. cepa AM plants increased up to 18 times that of NM plants. Similarly, plant growth of 27 A. fistulosum cultivars was enhanced by AMF, and increased up to 20 times that of the NM control in an extremely responsive cultivar (Tawaraya 

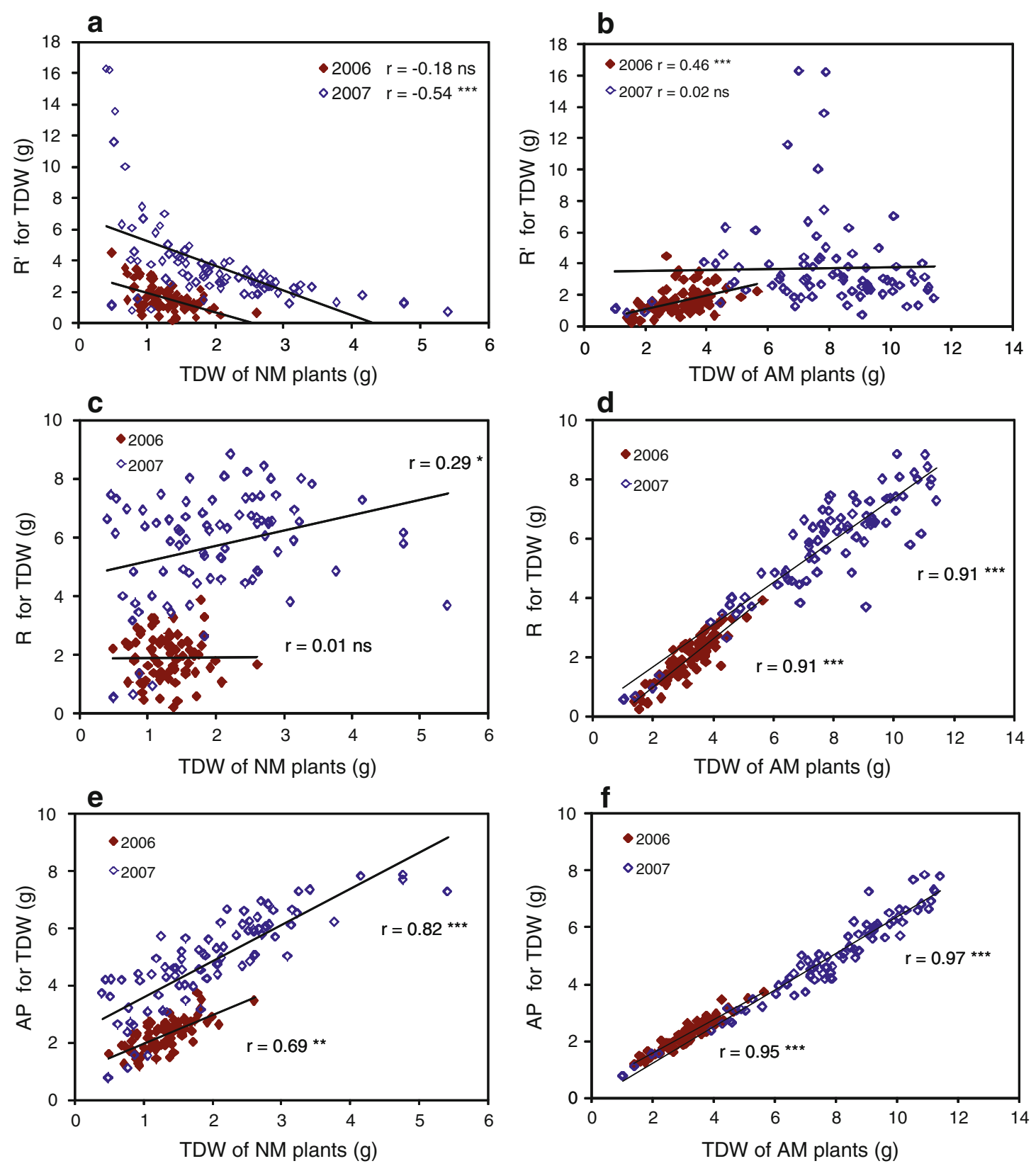

Fig. 3 Genetic variation in the tri-hybrid Allium population. a Relative mycorrhizal responsiveness $\left(\mathrm{R}^{\prime}\right)$ as a function of total dry weight (TDW) of non-mycorrhizal (NM) plants in experiments 2006 and 2007; b Idem, for mycorrhizal (AM) plants; c Absolute mycorrhizal responsiveness (R) as a function of TDW of NM plants in 2006 and

et al. 2001). Among cultivated species, onion and leek (A. porrum L.) are regarded as highly responsive to AMF (Miller et al. 1986; Plenchette et al. 1983). Such very high responsiveness to mycorrhiza of Allium species implies that these plants are unable to complete their life cycle in the absence of AMF, due to insufficient $P$ uptake and hence insufficient growth. This means that Allium species can be regarded as highly obligate mycorrhizal plants. The inability to grow in the absence of AMF was discussed

2007; d idem for AM plants; e Average performance (AP) as a function of TDW of NM plants in 2006 and 2007; $\mathbf{f}$ idem for AM plants. Pearson correlations (ns: $p>0.05 ; * p<0.05 ; * * p<0.01$; $* * * p<0.001)$

previously for onion (Charron et al. 2001), leek (Sasa et al. 1987) and for A. fistulosum (Tawaraya et al. 2001). Our results on the tri-hybrid genotypes confirmed this conclusion, even though a small number of genotypes showed a non-significant biomass increase in the mycorrhizal condition (Table 4; Fig. 1). This growth-inability has a major drawback when investigating the genetic basis for plant response to mycorrhiza because $\mathrm{R}$ and $\mathrm{AP}$ are then almost completely determined by the growth of the mycorrhizal 

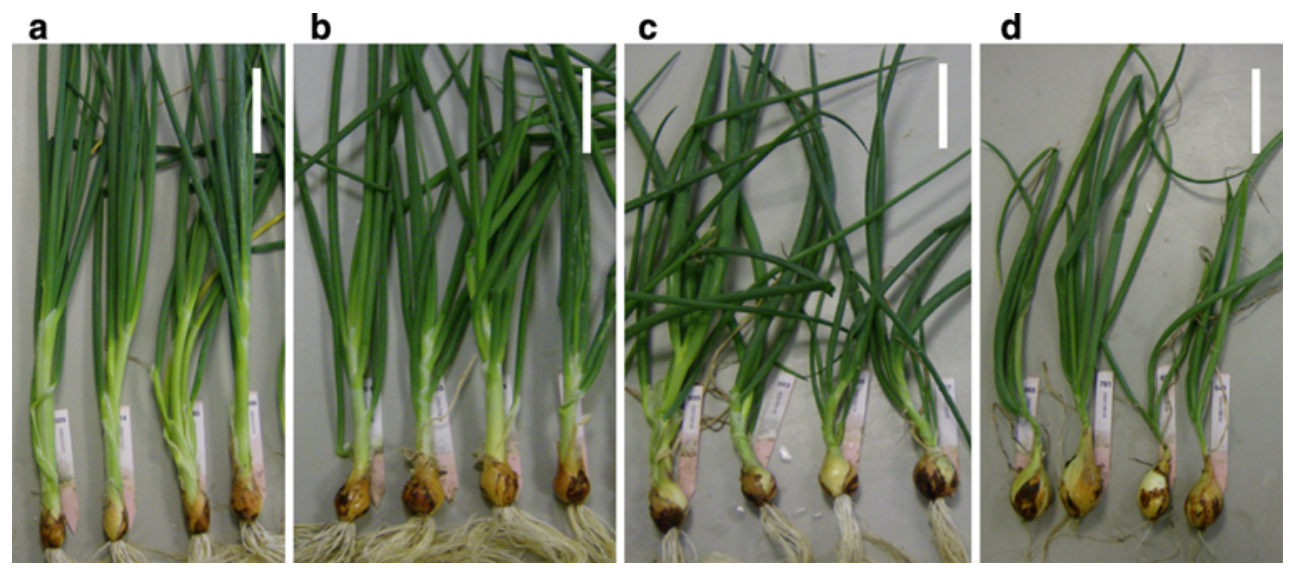

Fig. 4 Examples of four tri-hybrid genotypes classified according to the bulbing index (BI = bulb diameter/neck diameter), as follows: a null $(\mathrm{BI}=1.0-1.6)$, b low (1.6-2.4), $\mathbf{c}$ medium (2.4-2.7), and $\mathbf{d}$ high (>2.7) degree of bulbing. White bars $10 \mathrm{~cm}$ long

Table 4 Plant traits and indices for the response to AMF of tri-hybrid genotypes classified with regard to the level of bulbing

\begin{tabular}{|c|c|c|c|c|c|c|}
\hline \multirow[t]{2}{*}{ Traits } & \multicolumn{4}{|c|}{ Levels of bulbing } & \multicolumn{2}{|c|}{$\begin{array}{l}\text { Wald } \\
\text { statistic }\end{array}$} \\
\hline & Poor & Low & Medium & High & & pability \\
\hline \multicolumn{7}{|l|}{ Experiment 2006} \\
\hline $\mathrm{Nr}$ of observations & 18 & 22 & 18 & 12 & & \\
\hline $\begin{array}{l}\text { AM total dry } \\
\text { weight }(\mathrm{g})\end{array}$ & $3.52 \mathrm{a}$ & $3.43 \mathrm{a}$ & $3.08 \mathrm{ab}$ & $2.72 \mathrm{~b}$ & & 0.040 \\
\hline $\begin{array}{l}\text { AM leaf dry } \\
\text { weight }(\mathrm{g})\end{array}$ & $1.82 \mathrm{a}$ & $1.58 \mathrm{ab}$ & $1.38 \mathrm{~b}$ & $0.87 \mathrm{c}$ & & $<0.001$ \\
\hline $\begin{array}{l}\text { AM bulb dry } \\
\text { weight }(\mathrm{g})\end{array}$ & 1.65 & 1.80 & 1.76 & 1.85 & ns & 0.483 \\
\hline $\mathrm{Nr}$ of Leaves & 7.3 & 7.6 & 7.2 & 6.1 & ns & 0.208 \\
\hline $\mathrm{Nr}$ of roots & 24.4 & 27.2 & 25.6 & 24.7 & ns & 0.498 \\
\hline $\mathrm{R}(\mathrm{g})$ & $2.4 \mathrm{a}$ & $2.0 \mathrm{ab}$ & $1.7 \mathrm{bc}$ & $1.4 \mathrm{c}$ & & 0.003 \\
\hline AP $(g)$ & 2.3 & 2.4 & 2.2 & 2.0 & ns & 0.192 \\
\hline \multicolumn{7}{|l|}{ Experiment 2007} \\
\hline $\mathrm{Nr}$ of observations & 22 & 26 & 19 & 15 & & \\
\hline $\begin{array}{l}\text { AM total dry } \\
\text { weight }(\mathrm{g})\end{array}$ & $7.93 \mathrm{a}$ & $8.64 \mathrm{a}$ & $8.04 \mathrm{a}$ & $5.34 \mathrm{~b}$ & & $<0.001$ \\
\hline $\begin{array}{l}\text { AM leaf dry } \\
\text { weight }(\mathrm{g})\end{array}$ & $5.38 \mathrm{a}$ & $5.37 \mathrm{ab}$ & $4.78 \mathrm{~b}$ & $2.62 \mathrm{c}$ & & $<0.001$ \\
\hline $\begin{array}{l}\text { AM bulb dry } \\
\text { weight }(\mathrm{g})\end{array}$ & $2.55 \mathrm{~b}$ & $3.25 \mathrm{a}$ & $3.28 \mathrm{a}$ & $2.78 \mathrm{~b}$ & & 0.025 \\
\hline $\mathrm{Nr}$ of Leaves & $10.6 \mathrm{a}$ & $9.9 \mathrm{a}$ & $10.0 \mathrm{a}$ & $6.5 \mathrm{~b}$ & & $<0.001$ \\
\hline $\mathrm{Nr}$ of roots & 38.5 & 41.8 & 40.4 & 31.1 & ns & 0.064 \\
\hline $\mathrm{R}(\mathrm{g})$ & $6.0 \mathrm{a}$ & $6.1 \mathrm{a}$ & $6.2 \mathrm{a}$ & $3.9 \mathrm{~b}$ & & $<0.001$ \\
\hline $\mathrm{AP}(\mathrm{g})$ & $4.9 \mathrm{a}$ & $5.6 \mathrm{a}$ & $5.0 \mathrm{a}$ & $3.4 \mathrm{~b}$ & & $<0.001$ \\
\hline
\end{tabular}

Mean followed by the same letter for each trait (each row) do not differ $(p<0.05)$. REML analysis followed by Fischer-protected LSD-test, for square root transformed data. For R and AP see Table 2

plant. Consequently, selection for R or AP would imply selection for the largest plant, not selection for traits that specifically become enhanced by AMF.
The response to mycorrhiza has been expressed as relative mycorrhizal responsiveness $\left(\mathrm{R}^{\prime}\right)$, a dimensionless ratio indicating the weight difference between mycorrhizal and non-mycorrhizal plants as percentage of that of the non-mycorrhizal (Baon et al. 1993; Janos 2007; Sawers et al. 2010) or mycorrhizal plant (Plenchette et al. 1983). However, use of ratios with variable denominators may give misleading conclusions due to indirect effects (Righetti et al. 2007). In practice, a larger responsiveness can result from larger AM plants (numerator) or from smaller NM plants (denominator). In the current study, $\mathrm{R}^{\prime}$ was negatively correlated with weight of non-mycorrhizal plants (Fig. 3). The same negative relationship was reported for wheat (Hetrick et al. 1995), A. fistulosum (Tawaraya et al. 2001) and maize (Kaeppler et al. 2000). In fact, a negative correlation would likely occur in (almost) all circumstances. For that reason, the search for chromosomal regions or QTLs that are linked to $\mathrm{R}^{\prime}$ in order to breed for higher relative mycorrhizal responsiveness, would result in plants that produce less biomass when NM.

Therefore, the use of $\mathrm{R}^{\prime}$ was regarded unsatisfactory, which is in agreement with Sawers et al. (2010) and two alternative indices were considered: absolute responsiveness (R) and average performance (AP). The concept of $\mathrm{R}$ as used here is identical to the term $\mathrm{R}_{[\mathrm{P}]}$ as used by Janos (2007) for a designated concentration of available phosphorus. A difference is that Janos proposed to draw response curves along a P-gradient for AM and NM plants, and then to derive $R_{\max }$. A major disadvantage of that method is that $R_{\max }$ of different genotypes occurs at different P-levels (as is shown in Fig. 2 of Janos 2007), thereby hampering comparability of genotypes. In addition, determining response curves over a $\mathrm{P}$-gradient for a large number of genotypes, as is the case in the current study, is prohibitively time-consuming and expensive. Because Allium 
Table 5 QTLs for the indices for the response to AMF and plant traits in experiments 2006 and 2007

\begin{tabular}{|c|c|c|c|c|c|c|}
\hline \multirow[t]{2}{*}{ Traits $^{\mathrm{a}}$} & \multirow[t]{2}{*}{ Peak marker } & \multirow[t]{2}{*}{ Linkage group } & \multirow[t]{2}{*}{$\mathrm{LOD}^{\mathrm{b}}$} & \multicolumn{2}{|c|}{ Mean of the locus from } & \multirow{2}{*}{$\begin{array}{l}\text { Variance } \\
\text { explained }(\%)\end{array}$} \\
\hline & & & & A. roylei & A. fistulosum & \\
\hline \multicolumn{7}{|c|}{ Indices for the benefit from mycorrhiza (based on total plant dry weight) } \\
\hline \multirow[t]{2}{*}{ R 2006} & $\mathrm{P} 35 \mathrm{M} 47-278 \mathrm{~F}$ & Chrom 2 & $3.84 * *$ & 2.31 & 1.64 & 15.8 \\
\hline & E37M52A-301F & Chrom 6 & $4.08 * *$ & 1.54 & 2.24 & 13.5 \\
\hline \multirow[t]{3}{*}{ R 2007} & P31M35-247R & Chrom 2 & $3.70 *$ & 6.47 & 4.95 & 18.6 \\
\hline & P31M35-328R & Chrom 2 & $3.86^{* *}$ & 6.34 & 4.92 & 16.3 \\
\hline & P38M48-187R & Chrom 3 & $3.60 *$ & 6.32 & 4.94 & 15.2 \\
\hline \multirow[t]{4}{*}{ AP 2006} & P35M47-278F & Chrom 2 & $3.59 *$ & 2.49 & 2.02 & 19.6 \\
\hline & P38M48-187R & Chrom 3 & $3.13 *$ & 2.40 & 1.98 & 15.7 \\
\hline & E36M52C-86R & Chrom 4 & $3.00 *$ & 2.38 & 2.01 & 12.9 \\
\hline & P35M34-133F & Group 9 & $4.53 * *$ & 2.00 & 2.48 & 21.0 \\
\hline \multirow[t]{2}{*}{ AP 2007} & P31M35-328R & Chrom 2 & $4.00 * *$ & 5.21 & 4.04 & 13.2 \\
\hline & P31M33-401F & Group 9 & $4.98 * *$ & 4.01 & 5.66 & 24.7 \\
\hline \multicolumn{7}{|c|}{ Total plant dry weight ${ }^{\mathrm{c}}$} \\
\hline \multirow[t]{4}{*}{ AM 2006} & P35M47-278F & Chrom 2 & $3.44 *$ & 3.59 & 2.85 & 18.8 \\
\hline & E38M52T-156F & Chrom 6 & $3.00 *$ & 2.85 & 3.50 & 14.5 \\
\hline & P35M32-59R & Group 9 & $3.52 *$ & 2.83 & 3.51 & 15.3 \\
\hline & P38M48-187R & Chrom 3 & $3.57 *$ & 3.36 & 2.75 & 16.3 \\
\hline \multirow[t]{3}{*}{ AM 2007} & P31M35-328R & Chrom 2 & $4.89 * *$ & 8.68 & 6.70 & 17.6 \\
\hline & P38M48-187R & Chrom 3 & $3.57 *$ & 8.52 & 6.85 & 12.6 \\
\hline & P31M33-401F & Group 9 & $4.29 * *$ & 6.72 & 8.91 & 21.8 \\
\hline \multirow[t]{2}{*}{ NM 2006} & P38M48-187R & Chrom 3 & $3.64 *$ & 1.37 & 1.07 & 15.3 \\
\hline & P38M48-62R & Group 9 & $3.69 *$ & 1.07 & 1.37 & 16.0 \\
\hline NM 2007 & E35M52T-394R & Group 9 & $4.50 * *$ & 1.31 & 2.33 & 23.5 \\
\hline \multicolumn{7}{|c|}{ Other plant traits of AM plants } \\
\hline \multirow[t]{2}{*}{ Height 2006} & P35M32-228R & Chrom 2 & $5.47 * *$ & 63.5 & 52.0 & 28.7 \\
\hline & P38M48-187R & Chrom 3 & $3.49 *$ & 60.7 & 51.2 & 19.3 \\
\hline Height 2007 & P38M48-187R & Chrom 3 & $5.85 * *$ & 81.2 & 68.6 & 22.4 \\
\hline \multirow[t]{3}{*}{ LDW $2006^{\mathrm{c}}$} & $\mathrm{P} 35 \mathrm{M} 47-278 \mathrm{~F}$ & Chrom 2 & $4.83 * *$ & 1.80 & 1.21 & 20.8 \\
\hline & P38M48-187R & Chrom 3 & $3.25 * *$ & 1.68 & 1.11 & 15.8 \\
\hline & P31M33-167R & Chrom 6 & $3.04 *$ & 1.24 & 1.82 & 12.4 \\
\hline \multirow[t]{2}{*}{ LDW $2007^{\mathrm{c}}$} & P38M48-187R & Chrom 3 & $2.86^{*}$ & 5.40 & 4.01 & 12.8 \\
\hline & P31M35-306F & Chrom 6 & $3.91 * *$ & 4.14 & 5.27 & $18 . .8$ \\
\hline BDW $2006^{\mathrm{c}}$ & P38M48-62R & Group 9 & $5.70 * *$ & 1.23 & 1.37 & 28.0 \\
\hline BDW $2007^{\mathrm{c}}$ & P31M33-401F & Group 9 & $5.02 * *$ & 1.56 & 1.81 & 24.6 \\
\hline Nr Roots 2006 & P38M48-118R & Group 9 & $3.79 * *$ & 22.1 & 27.5 & 19.1 \\
\hline Nr Roots 2007 & P31M33-401F & Group 9 & $3.74 * *$ & 34.8 & 45.6 & 17.9 \\
\hline
\end{tabular}

$A M$ total dry weight in the treatment inoculated with $G$. intraradices; $N M$ total dry weight in the non-inoculated treatment. $L D W$ leaves dry weight, $B D W$ bulb/false-stem dry weight, $\mathrm{Nr}$ Roots Number of stem-borne roots per plant

$* * p<0.01, * p<0.05, n s$ not significant

${ }^{\text {a }}$ For R and AP see Table 2

b Calculated using multiple QTL mapping in MapQTL 5.0

${ }^{c}$ Square-root transformed before analysis

tri-hybrid genotypes showed a large response to AMF, $\mathrm{R}$ was significantly correlated with biomass of mycorrhizal plants (Fig. 3). Onion roots obtained from farmers fields in the Netherlands were all colonized by mycorrhizal fungi to a high degree (Galván et al. 2009). Therefore, the mycorrhizal condition is the normal condition under which onions are grown. Consequently, selection for high $\mathrm{R}$ equals selection for genotypes that perform best under 'normal' 


\section{Chromosome 2}

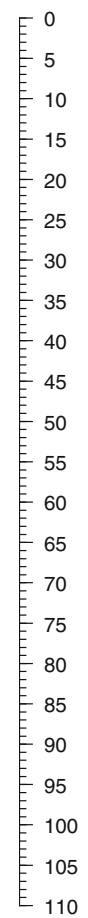

Chromosome 3

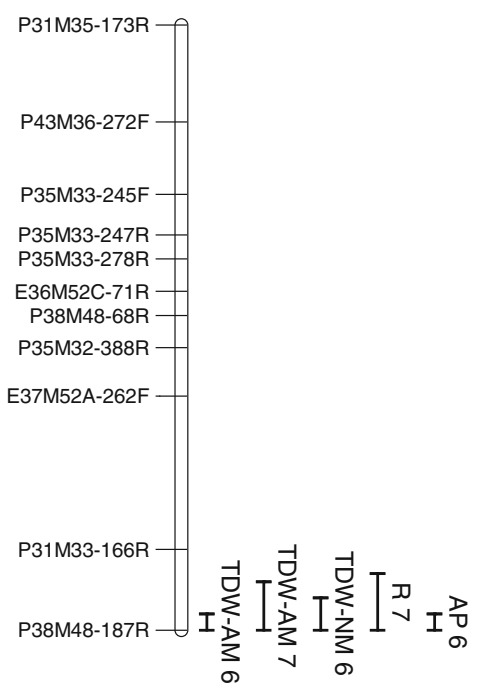

Linkage group 9

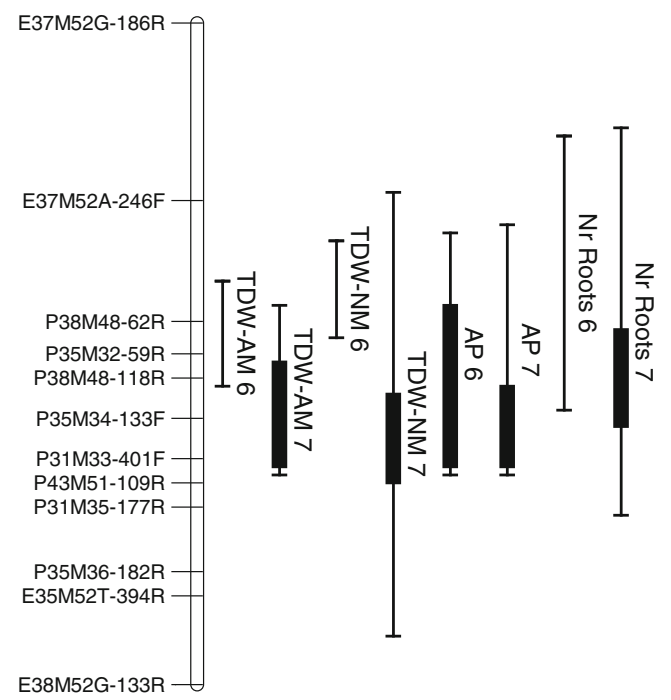

Fig. 5 QTLs on the linkage map of the RF-hybrid for absolute mycorrhizal responsiveness (R), average performance (AP), total dry weight (TDW) and the number of stem-borne roots of the plants inoculated with Glomus intraradices (AM) and non-mycorrhizal
(NM) plants in experiments 2006 and 2007. The lines show the LOD region above threshold value $(p<0.05)$ and solid bars represents 1 LOD interval from the maximum LOD score if fitted within the significant region. The ruler indicates Kosambi's distances in $\mathrm{cM}$ (i.e., mycorrhizal) conditions. However, for other plant species and genotypes that show a lower response to AMF, selection for R may also involve selection for small plants in the non-mycorrhizal condition. Such genotypes are unlikely to provide any mycorrhizal beneficial effects in combination with plant material with a high-yielding background in advanced breeding generations (Sawers et al. 2008).

To avoid problems with $\mathrm{R}$ and $\mathrm{R}^{\prime}$, an additional index was developed for plant breeders and growers: average performance (AP). This index could be relevant to use in addition to $\mathrm{R}$, as a high value of AP in the tri-hybrid generally indicates that genotypes perform on average well in a range of conditions with variable mycorrhizal inoculum availability (Fig. 1). Selection for yield stability under conditions where mycorrhizal inoculum potential is variable (or even absent) could be achieved by selecting for high AP as in this study, AP correlated well with biomass of mycorrhizal plants. Whether AP is also useful for plant species or genotypes that show lower response to AMF needs to be established.

Therefore, past selection for high-yielding onion genotypes, the ultimate aim of plant breeding, may have selected for onions with a higher benefit from mycorrhiza. This hypothesis is in contrast to the hypothesis proposed by
Hetrick et al. (1993, 1995) and Zhu et al. (2001) who, based on a comparison of old and modern cultivars, concluded that modern plant breeding led to a reduced mycorrhizal responsiveness. Their data also indicate a reduced $\mathrm{R}$ for modern cultivars compared to old cultivars. A possible explanation for these contradictory outcomes is that modern wheat breeding, by focusing on yield stability, probably selected for genotypes capable to grow where there is limited or absent AMF-inoculum (Sawers et al. 2008). For onion and its relatives, which are so dependent on AMF that they cannot complete their life cycle without AMF, breeding has apparently never succeeded in enhancing the plant's intrinsic capability to acquire sufficient $P$ without AMF.

Genetic analysis of the response to mycorrhiza in Allium

This research identified chromosomal regions linked to quantitative 'traits' involved in response to mycorrhiza in an A. cepa $\times($ A. roylei $\times$ A. fistulosum $)$ population. We put trait between inverted commas, because in a strict sense properties like $\mathrm{R}^{\prime}$, $\mathrm{R}$ or AP are not plant traits, but the result of plant-AMF-soil interactions (Janos 2007). Three QTLs were identified for R or AP located on the central 
part of chromosome 2, a distal part of chromosome 3 and linkage group 9. These QTLs were identified both in experiments 2006 and 2007.

These three chromosomal regions also harboured QTLs for dry weight of AM plants. Considering the highly significant correlations between biomass of AM plants, $\mathrm{R}$ and AP (Table 3; Fig. 3) this result is not surprising as these parameters are statistically interdependent. On linkage group 9, also a QTL was found for dry weight of NM plants. This finding is consistent with the correlation found between weight of AM and NM plants and indicates that plants that grow better in a P-deficient soil without mycorrhiza, retain that ability in the mycorrhizal condition. Large NM values were obtained when $A$. fistulosum alleles were present in the QTL region on linkage group 9. This result corresponds with the finding that $A$. fistulosum performed better in the NM treatment than A. roylei (Tables 3, 5).

QTLs for both R and AP were found on chromosomes 2 and 3, but some QTLs were only recovered in one of the 2 years that the experiment took place. Despite the highly significant correlations between growth of AM plants in both years, and a somewhat lower but still significant correlation between both years for NM plants, experimental variation resulted in differences between experiments in detected QTLs. Such variation should be reason for a cautionary note regarding the genetic basis for such 'traits'.

A counterintuitive result is that QTLs on chromosomes 2 and 3 can be ascribed to $A$. royle $i$ alleles, because this species had the lowest weight of AM and NM plants and thus the lowest values for R and AP. A positive contribution by the $A$. roylei background (in combination with $A$. cepa and A. fistulosum genes) may be the result of nonadditive effects. Transgressive segregation observed for trihybrid genotypes, with values for R, AP, and total dry weight of AM plants exceeding both the minimum and maximum of the parental values is consistent with such a hypothesis (Table 3 ).

Transgressive segregation for the number of stemborne roots in the tri-hybrid population was less evident, as A. fistulosum had high numbers of roots in both years. One QTL for the number of stem-borne roots of AM plants was found on linkage group 9, associated with $A$. fistulosum alleles. This QTL co-segregated with QTLs for AP and total dry weight of AM and NM plants. Again, this observation is consistent with the positive correlation between these traits and number of stemborne roots. Because A. roylei also formed a relatively large number of stem-borne roots, the variation for this trait between A. fistulosum and A. roylei may be limited. Further analysis of plants obtained from a backcross with A. cepa may allow the finding of more variation and the identification of more QTLs for the number of roots. De
Melo (2003) did not find significant QTLs for the number of stem-borne roots, a difference that may be caused by the smaller set of genotypes that was analyzed. A QTL from A. fistulosum for the presence of lateral roots was located on chromosome 1 (LOD 6.0), and a QTL for the length of fine roots was located on chromosome 6 (LOD 4.2) (De Melo 2003), two traits that contribute to a denser and more efficient rooting system (Lynch 2007).

The comparison of tri-hybrid genotypes in classes with different degrees of bulbing showed that R, AP and total dry weight were lower for the group with high degree of bulbing. The lowest R and AP values were observed for genotypes that presented early bulbing and senescence of the leaves. It would seem, therefore, that selection for bulbing would select against maximisation of plant benefit by AMF. However, several cautionary notes are in order. First, the trade off between bulbing and R/AP was only apparent for some genotypes with the highest degree of bulbing, not for genotypes with medium degree of bulbing. Second, the lower biomass of bulbing genotypes was most apparent in those genotypes that also showed early leaf senescence. Further research on the underlying relationship between early bulbing and benefit from AMF is required.

\section{Concluding remarks}

The latter conclusion raises a final question: is there room for a contribution from A. fistulosum or A. roylei to improve the benefit from mycorrhiza in A. cepa? Both species have a much better developed rooting system than A. cepa. A better rooting system may lead to a lower benefit from AMF in grasses (Schultz et al. 2001), but this was not the case in Allium. The absence of a trade off between an improved rooting system and a large benefit from mycorrhiza implies that A. fistulosum (and A. roylei) can be used to improve the rooting system of $A$. cepa while maintaining the benefit from mycorrhiza. Introgression of A. fistulosum genes into A. cepa could therefore contribute to improved performance in environments where mycorrhizal inoculum is limited, due to an improved rooting system, while maintaining its benefit from mycorrhiza.

An interesting result was the transgressive segregation observed for tri-hybrid genotypes. It seems that the combination of three genomes expands the genetic variation for plant growth and the response to mycorrhiza. Further research is needed to address whether this variation can be exploited in onion breeding, especially regarding the translation of this potential biomass improvement into the development of a larger bulb. In this regard, it is promising that at least some genotypes with high degree of bulbing 
also possessed large R, AP and total plant weight values. Therefore, by either the large benefit from mycorrhiza, the large rooting system, or the transgressive segregation for plant biomass, new opportunities arise from Allium introgressions towards the development of robust onion cultivars.

Acknowledgments Thanks are due to Dr. Y. Kapulnik, who kindly provided the mycorrhizal inoculum for this research. We thank B. Kronenburg and B. Henken for technical assistance during micropropagation of plant material, A. Isdiyanto, J. van de Berg and G. Versteeg for assistance during greenhouse experiments, and Dr. R. Voorrips for valuable comments on QTL analysis. Critical and constructive comments on a previous version of the manuscript by two anonymous reviewers are also gratefully acknowledged. This work was funded by the Dutch Ministry of Agriculture, Nature and Food quality as part of Programme 388-II Plant Breeding for Organic Farming. G. A. Galván thanks Alban Programme of the European Union (Fellowship E03D02847UR), PDT-CONICYT Uruguay (Fellowship S/C/BE/20/09), and the NFP (The Netherlands) for their financial support.

Open Access This article is distributed under the terms of the Creative Commons Attribution Noncommercial License which permits any noncommercial use, distribution, and reproduction in any medium, provided the original author(s) and source are credited.

\section{References}

Alkan N, Gadkar V, Coburn J, Yarden O, Kapulnik Y (2003) Quantification of the arbuscular mycorrhizal fungus Glomus intraradices in host tissue using real-time polymerase chain reaction. New Phyt 161:877-885

Bååth E, Hayman SD (1984) Effect of soil volume and plant density on mycorrhizal infection and growth response. Plant Soil 77:373-376

Baon JB, Smith SE, Alston AM (1993) Mycorrhizal responses of barley cultivars differing in P efficiency. Plant Soil 157:97-105

Bosch-Serra AD, Currah L (2002) Agronomy of onions. In: Rabinowitch HD, Currah L (eds) Allium crop science: recent advances. CAB International, Wallingford, pp 187-232

Charron G, Furlan V, Bernier-Carou M, Doyon G (2001) Response of onion plants to arbuscular mycorrhizae. 1. Effects of inoculation method and phosphorus fertilization on biomass and bulb firmness. Mycorrhiza 11:187-197

De Melo PE (2003) The root systems of onion and Allium fistulosum in the context of organic farming: a breeding approach. Ph.D. thesis. Wageningen University, The Netherlands

Galván GA, Parádi I, Burger K, Baar J, Kuyper TW, Scholten OE, Kik C (2009) Molecular diversity of arbuscular mycorrhizal fungi in onion roots from organic and conventional farming systems in the Netherlands. Mycorrhiza 19:317-328

Gao X, Kuyper TW, Zou C, Zhang F, Hoffland E (2007) Mycorrhizal responsiveness of aerobic rice genotypes is negatively correlated with their zinc uptake when nonmycorrhizal. Plant Soil 290:283-291

George E, Marschner H, Jakobsen I (1995) Role of arbuscular mycorrhizal fungi in uptake of phosphorus and nitrogen from soil. Crit Rev Biotech 15:257-270
Gosling P, Hodge A, Goodlass G, Bending GD (2006) Arbuscular mycorrhizal fungi and organic farming. Agric Ecosyst Environ 113:17-35

Greenwood DJ, Gerwitz A, Stone DA, Barnes A (1982) Root development of vegetable crops. Plant Soil 68:75-96

Hayman DS, Mosse B (1971) Plant growth responses to vesiculararbuscular mycorrhiza. I. Growth of Endogone-inoculated plants in phosphate-deficient soils. New Phyt 70:19-27

Hetrick BAD, Wilson GWT, Cox TS (1993) Mycorrhizal dependence of modern wheat cultivars and ancestors: a synthesis. Can J Bot 71:512-518

Hetrick BAD, Wilson GWT, Cox TS (1995) Chromosome location of mycorrhizal responsive genes in wheat. Can $\mathrm{J}$ Bot 73:891-897

Hoeksema JD, Chaudhary VB, Gehring CA, Johnson NC, Karst J, Koide RT, Pringle A, Zabinski C, Bever JD, Moore JC, Wilson GWT, Klironomos JN, Umbanhowar J (2010) A meta-analysis of context-dependency in plant response to inoculation with mycorrhizal fungi. Ecol Lett 13:394-407

Janos DP (2007) Plant responsiveness to mycorrhizas differs from dependence upon mycorrhizas. Mycorrhiza 17:75-91

Jansen RC (1993) Interval mapping of multiple quantitative trait loci. Genetics 135:205-211

Jansen RC, Stam P (1994) High resolution of quantitative traits into multiple loci via interval mapping. Genetics 136:1447-1455

Kaeppler SM, Parke JL, Mueller SM, Senior L, Stuber C, Tracy WF (2000) Variation among maize inbred lines and detection of quantitative trait loci for growth at low phosphorus and responsiveness to arbuscular mycorrhiza fungi. Crop Sci 40:358-364

Khrustaleva LI, Kik C (1998) Cytogenetical studies in the bridge cross Allium cepa $\times($ A. fistulosum $\times$ A. roylei $)$. Theor Appl Gen 96:8-14

Khrustaleva LI, Kik C (2000) Introgression of Allium fistulosum into A. cepa mediated by A. roylei. Theor Appl Genet 100:17-26

Khrustaleva LI, De Melo PE, Van Heusden AH, Kik C (2005) The integration of recombination and physical maps in a largegenome monocot using haploid genome analysis in a trihybrid Allium population. Genetics 169:1673-1685

Lekberg Y, Koide RT (2005) Is plant performance limited by abundance of arbuscular mycorrhizal fungi? A meta-analysis of studies published between 1988 and 2003. New Phyt 168:189-204

Lynch JP (2007) Roots of the second green revolution. Austr J Bot $55: 493-512$

McGonigle TP, Miller MH, Evans DG, Fairchild GL, Swan JA (1990) A new method which gives an objective measure of colonization of roots by vesicular-arbuscular mycorrhizal fungi. New Phyt 115:495-501

Mengel K, Kirkby EA (2001) Principles of plant nutrition, 5th edn. Kluwer, Dordrecht

Miller JC, Rajapakse S, Garber RK (1986) Vesicular-arbuscular mycorrhizae in vegetable crops. Hortscience 21:974-984

Parke JL, Kaeppler SW (2000) Effects of genetic differences among crop species and cultivars upon the arbuscular mycorrhizal symbiosis. In: Kapulnik Y, Douds DD (eds) Arbuscular mycorrhizas: physiology and function. Kluwer, Dordrecht, pp 131-146

Plenchette C, Fortin JA, Furlan V (1983) Growth responses of several plant species to mycorrhizae in a soil of moderate P-fertility I. Mycorrhizal dependency under field conditions. Plant Soil 70:199-209

Plenchette C, Clermont-Dauphin C, Meynard JM, Fortin JA (2005) Managing arbuscular mycorrhizal fungi in cropping systems. Can J Plant Sc 85:31-40

Portas CAM (1973) Development of the root systems during the growth of some vegetable crops. Plant Soil 39:507-518 
Powell CL, Clark GE, Verberne NJ (1982) Growth response of four onion cultivars to several isolates of VA mycorrhizal fungi. $\mathrm{N} \mathrm{Z}$ J Agric Res 25:465-470

Righetti TL, Sandrock DR, Strik B, Vasconcelos C, Moreno Y, Ortega-Farias S, Bañados P (2007) Analysis of ratio-based responses. J Am Soc Hortic Soc 132:3-13

Rossing WAH, Zander P, Josien E, Groot JCJ, Meyer BC, Knierim A (2007) Integrative modelling approaches for analysis of impact of multifunctional agriculture: a review for France, Germany and the Netherlands. Agric Ecosyst Environ 120:41-57

Ryan MH, Graham JH (2002) Is there a role for arbuscular mycorrhizal fungi in production agriculture? Plant Soil 244:263-271

Sasa M, Zahka G, Jakobsen I (1987) The effect of pretransplant inoculation with VA mycorrhizal fungi on the subsequent growth of leeks in the field. Plant Soil 97:279-283

Sawers RJH, Gutjahr C, Paszkowski U (2008) Cereal mycorrhiza: an ancient symbiosis in modern agriculture. Trends Plant Sci 13:93-97

Sawers RJH, Gebreselassie MN, Janos DP, Paszkowski U (2010) Characterizing variation in mycorrhiza effect among diverse plant varieties. Theor Appl Genet 120:1029-1039

Schultz PA, Miller RM, Jastrow JD, Rivetta CV, Bever JD (2001) Evidence of a mycorrhizal mechanism for the adaptation of Andropogon gerardii (Poaceae) to high- and low-nutrient prairies. Amer J Bot 88:1650-1656
Stribley DP (1990) Mycorrhizal associations and their significance. In: Rabinowitch HD, Brewster JL (eds) Onions and allied crops. CRC Press, Boca Raton, vol 2, pp 85-101

Tawaraya K, Tokairin K, Wagatsuma T (2001) Dependence of Allium fistulosum cultivars on the arbuscular mycorrhizal fungus, Glomus fasciculatum. Appl Soil Ecol 17:119-124

Van Heusden AW, Shigyo M, Tashiro Y, Vrielink-van Ginkel R, Kik C (2000) AFLP linkage group assignment to the chromosomes of Allium cepa L. via monosomic addition lines. Theor Appl Genet 100:480-486

Van Ooijen JW, Voorrips RE (2001) JoinMap 3.0: software for the calculation of genetic linkage maps. Plant Research International, Wageningen

Van Ooijen JW, Boer MP, Jansen RC, Maliepaard C (2002) MapQTL 4.0: software for the calculation of QTL positions on genetic maps. Plant Research International, Wageningen

Voorrips RE (2002) MapChart: software for the graphical presentation of linkage maps and QTLs. J Hered 93:77-78

Vos P, Hogers R, Bleeker M, Reijans M, Van de Lee T, Hornes M, Frijters A, Pot J, Peleman J, Kuiper M, Zabeau M (1995) AFLP: a new technique for DNA fingerprinting. Nucleic Acids Res 23:4407-4414

Zhu YG, Smith SE, Barrit AR, Smith FA (2001) Phosphorus (P) efficiencies and mycorrhizal responsiveness of old and modern wheat cultivars. Plant Soil 237:249-255 